\title{
The Impact of Impulse Buying and Network Platforms on Consumer Purchasing Behaviour: A Case Study of a Technical Product
}

\author{
Xuan WEN, Yiran LI, Qihua LIU
}

\begin{abstract}
This paper investigates the effects of impulse buying and network platforms on the online purchasing behaviour for experience goods using a 2 (low impulse buying tendency vs. high impulse buying tendency) $\times 2$ (mobile platform vs. computer platform) between-subjects factorial experiment.A technical product is a typical type of experience good. To increase the external validity of the conclusions, this study takes software as a technical product and employs an online scenario-simulated experiment to collect data. The results indicate that low impulse consumers tend to spend less money and conduct more stringent budget control when purchasing a technical product. However, no significant difference existed between high and low impulse consumers regarding the purchasing decision. Furthermore, consumers who shop on a mobile platform tend to spend more money, conduct looser budget control and make more careful purchasing decisions. In addition, a remarkable effect also exists between impulse buying and network platforms regarding the average viewing time of the single page and the commodity details page.
\end{abstract}

Keywords: experience good; impulse buying; network platforms; purchasing behaviour; technical product

\section{INTRODUCTION}

During the last decades, online shopping has experienced rapid growth and dramatic change. Even further, it has supplanted brick-and-mortar stores in certain circumstances. After mobile devices attained their space and market share, the online shopping buying trend for consumers shifted from "click" to "tap" by offering valueadded benefits such as unlimited mobility, peer-to-peer communication and rapid disbursement [1]. Given the remarkable sales growth fuelled by online shopping, online retailers need to understand clearly the characteristics that can increase consumers' desire to purchase. In the offline retail market, impulse buying has contributed significantly to sales by stimulating consumers' appetite for buying and reducing their self-control [2]. By sorting out the relevant research on impulsiveness in the marketing and psychology literature, this paper finds that the impulse buying tendency is a fairly unique personal trait and can be easily affected by person-related variables.

Consistent with psychologists' viewpoint that impulsive behaviour varies with individual proclivity, consumer behaviour researchers assert that shoppers vary in their impulse buying tendencies [3]. Many studies have shown that the impulse buying tendency may affect purchasing behaviour, emotional arousal and online buying intentions. However, few researchers study the process of searching for information from an impulse buying perspective. In the present study, the authors explore how impulse buying affects online consumers' information search and budget control behaviour.

A technical product is a kind of technological achievement that has used value for the purpose of exchange [4]. A technical product occupies a critical position in the social life of residents. It has a wide range of uses and utility value in civilian fields, such as intelligent video surveillance, virtual reality and humancomputer interactions. A technical product is a typical kind of experience good. Experience and search goods are the two main types of products [5]. According to Klein's [6] definition, experience goods are defined as commodities with chief distinguishing features and a quality that cannot be known until it is purchased or used, or its information- seeking process is time-consuming and/or more difficult to achieve than a direct product experience. A search good refers to a commodity for which all information can be achieved before its purchase. Generally, experience goods rely heavily on psychological and informational inputs in their choice decisions, whereas search goods provide more search, inspect and compare options [7]. Many forms of technical products exist, which are usually divided into two categories: software technology commodities and hardware technology commodities. The software in software technology commodities can only be traded through online shopping. Therefore, further exploring consumers' online purchasing behaviour when buying a technical product is necessary. Currently, studies on this topic in the open literature are few.

Two modern channels exist for firms to reach out to their online customers: E-commerce and M-commerce [8]. Traditionally, M-commerce has been a natural prolongation and one of the developing mainstreams of Ecommerce, which allows shoppers to interact with each other in the wireless network environment whenever and wherever they want [9]. In this thesis, the researchers collectively refer to the mobile transaction platform as the mobile platform and the computer platform, accordingly. Although several types of research on the mobile and computer platforms' consumer buying behaviour have significant achievements, very few attempts have been made to systemically investigate the differences between these two platforms of online behaviour.

Finally, most studies on impulse buying have focused on the computer platform. With the rapid rise of the massive China Mobile Internettide, research on impulse buying on the mobile platform has already attracted much attention and has become a new and hot research field. Furthermore, different equipment, as well as the interactive mode, call for varying degrees of user experience [10]. The researchers expect that consumers with different levels of impulse buying tendencies will have different browsing behaviour on these two platforms. In other words, the interactive effect between impulse buying and network platforms may inevitably affect consumer search behaviour. 
In sum, different from past research that focused on the cognition and attitude related to online consuming behaviour, the purpose of this study is to examine the difference in consumers' consumption behaviour when buying a technical product under the influence of impulse buying and the cross-platform environment, as well as to propose counter measures and suggestions for online stores to increase sales and facilitate future development. The structure of this paper is as follows. In the next section, the researchers describe the theoretical background and propose research hypotheses. In the third and fourth sections, the researchers introduce the methodology and the results of the hypotheses testing. Finally, the researchers discuss and analyse the experimental results and implications and provide suggestions for future research.

\section{THEORETICAL BACKGROUND \\ 2.1 Impulse Buying}

A detailed review of the extant literature indicates that impulse buying is virtually unplanned and unexpected behaviour [11]. Consumers' internal tendencies are the main constraint on impulse buying behaviour, and the weaker the self-control, the easier for impulsive buying behaviour to occur [3]. Traditionally, the influencing factors of impulse buying include external stimuli and the shopping environment, internal stimuli, scenarios and products and diverse demographic and socio-cultural aspects, for which internal stimuli indicate individuals with different personality characteristics [12]. To some extent, the researchers refer to these internal personality characteristics as the impulse buying tendency.

Traditionally, the impulse buying tendency includes some attribute values, such as normative evaluations, purchase intention, self-control and gender. Moreover, these traits relate to consumers' family background and socioeconomic status [13]. In general, as an intrapersonal tendency without regard to actual demand and its influence on financial expenditures, impulse buying has profound implications on consumers' purchasing practices. Specifically, consumers with strong impulse buying tendencies have more credit cards and higher overdraft limits than those with weak impulse buying tendencies [14]. For these reasons, arguably, high impulse consumers can more easily connect external information with the internal emotions that contribute to producing impulse purchasing. Moreover, consumers' impulse buying tendencies and emotional states are positively correlated with impulsive buying behaviour, particularly in a network environment [15]. In summary, consumers' intrinsic impulsive purchasing traits, as a major factor that drives impulsive consumption, are correlated with spending limits regardless of whether online or offline.

The term "experience" in experience goods covers the concept of consumers objectively evaluating products' empirical value based on their experience and then assigning this value to merchandise, services, brands, or technology [16]. In other words, consumers who have not yet bought experience goods cannot accurately perceive the quality of the commodity before the purchase. Conversely, most of them prefer "following their own path" as long as the product's internal standards achieve the desired effect. Partly for this reason, experience goods are also referred to as "entertainment products" [6]. Usually, consumers who have more opportunities to enjoy a variety of interesting elements will be more sensitive to price and advertising. In this shopping circumstance, consumers have a stronger desire to buy because they can indulge themselves in the amusement, pleasure, fun and enjoyment of experience goods. To increase the entertainment after purchasing experience goods, high impulse online shoppers may be relatively unconcerned about whether they are paying too much. As a kind of experience good, technical products also have these features. Therefore, through this categorization and analysis, the researchers have developed the following hypotheses for a technical product.

H1: All else being equal, during an online shopping trip for a technical product, consumers with low impulse buying tendencies execute more stringent budget control relative to consumers with high impulse buying tendencies.

The intensity of the impulse buying tendency varies from person to person [3]. This tendency affects consumers' decisions about the time allocated to shopping, and they are influenced during the decision-making stage before buying goods [17]. Especially in a network environment, impulsive consumers prefer to avoid spontaneous social interactions and produce motivations given the variety of products and searches for information. Because of this urgent need to achieve "a sense of belonging" that is perceived to be achieved by purchasing one's favourite commodities, high impulse consumers more easily make a purchasing decision. Therefore, the researchers have developed the following hypothesis for a technical product.

H2: All else being equal, during an online shopping trip for atechnical product, consumers with low impulse buying tendencies make more difficult purchasing decisions relative to consumers with high impulse buying tendencies.

\subsection{Network Platforms}

Since 2000, M-commerce has attracted the attention of a large number of practitioners and scholars. Compared with the traditional Internet, the mobile Internet can support individuation information services more freely, frequently and simultaneously [18]. M-commerce has four unique characteristics: 1) it can help facilitate transactions anytime and anywhere because of the ubiquitous accessibility of the mobile Internet; 2) a mobile device basically targets a single user; to accommodate the needs of a special user community, the researchers can provide them with personalized applications that have representative information or services; 3 ) individual users can use a mobile device for activities, such as social networks, scheduled events, e-mail and map search or directions; and 4) mobile devices' small screens and low availability limit the long-term and complicated use of Mcommerce passage, which is not suitable for data-rich interactions. Correspondingly, page content on mobile devices must be more streamlined and offer less sophisticated navigation to facilitate browsing [19].

It is worth noting that interactive media and networks can help consumers reduce search costs and gather 
additional information before making purchasing decisions [5]. Moreover, compared with computers that cannot be used flexibly, mobile devices can give consumers more opportunities to browse online merchandise. Through the combination of experience goods' hedonic attributes and the mobile platform, researchers can develop strengths and circumvent weaknesses and, hence, design merchandise displays to more effectively increase online sales. Thus, consumers will likely buy more products when their budget control is relaxed and when using a mobile platform to purchase experience goods.

Building on this analysis, the researchers propose the following hypothesis for a technical product.

H3: All else being equal, during an online shopping trip for a technical product, consumers shopping on the mobile platform execute weaker budget control than do consumers using the computer platform.

Currently, many scholars have studied how consumers collect and process information to make decisions. Different types of information and distinct cognitive processes may affect the path of information collection, the quantity of information and the time to process each message [20]. Normally, consumers continue to search for better products until marginal costs exceed marginal efficiency. However, mobile devices usually provide a low level user interface and impede information collection because of the small screen and low availability. Therefore, consumers are unlikely to adopt mobile devices when engaging in a positive and comprehensive search [21].

In addition, information on experience goods is subjective and imprecise, which causes consumers to tend to use more online information and take more time to browse each commodity page than those who purchase search goods. More specifically, when consumers buy experience goods, they often need to contrast more product information to judge whether the commodity meets their expectations and is worth the price. Above all, browsing more products to perceive different "expertise-based" qualities, as well as the strong orientation of the information search on the mobile platform, makes it more difficult for consumers to make a purchasing decision. Thus, the researchers suggest the following hypothesis for a technical product.

H4: All else being equal, during an online shopping trip for a technical product, consumers shopping on the mobile platform face greater difficulty making purchasing decisions than do consumers using the computer platform.

\subsection{Interaction Effect between Impulse Buying and Network Platforms}

Although the younger generation collects the relevant information before making a purchase decision, they are more likely to be stimulated to engage in impulsive buying behaviour because the impulsiveness gives them a sense of satisfaction and spontaneity [11]. Because consumers' purchase intention truly has some connection to psychological factors, they must rely on their intrinsic impulse buying tendencies to make decisions when exposed to various purchase choices [22]. To avoid these emotions, all consumers can do is restrict themselves to avoid impulsive purchasing behaviour. In a sense, regardless of whether purchases are made offline or online on different platforms, impulse buying - as the essence of human nature - has been shown to play an indispensable role in consumer behaviour analysis.

In the context of a computer platform, most of the extant literature on commodity types can be divided into two areas: 1) recognizing goods' properties to study consumers' cognition of attributes; and 2) from the angle of behaviour to discuss how consumers obtain information and make purchasing decisions under the effect of goods' properties. A dearth of information, research and codified knowledge exists on the relationship between the mobile platform and commodity types. Nonetheless, because of services, user interaction patterns are not the same for mobile and computer platforms, and the researchers assume that product types and consumers' behaviour on mobile devices have an inherent relationship that is very different from the computer platform.

Two variables are most commonly used in the processtracking literature to reflect consumers' searching behaviour: 1) the average amount of time per acquisition, and 2) the number of acquisitions. The notion of the average amount of time per acquisition is similar to the time that a consumer spends evaluating information on a Web page, and the number of acquisitions is similar to the number of Web pages that a consumer accesses [23]. To better explain the interaction between impulse buying and network platforms on consumer behaviour, the researchers use the first variable and divide it into two dimensions: the primary depth of a search as the time spent browsing a Web page and the secondary depth of a search as the time browsing a commodity details Web page.

Thus, on the basis of the previous lines of reasoning, the researchers developed the following hypotheses.

H5: An interaction effect exists between impulse buying and network platforms regarding the time spent browsing a Web page.

H6: An interaction effect exists between impulse buying and network platforms regarding the time spent browsing the commodity details Web page.

\section{METHODS}

\subsection{Research Design}

The researchers tested the hypotheses using a $2 \times 2$ between-subjects factorial experiment with two impulse buying tendencies (i.e., low impulse buying tendency and high impulse buying tendency) and two network platforms (i.e., mobile platform and computer platform) and with college students as the object. This study adopted an online scenario-simulated experiment to collect data to build an accurate picture of how individual factors or the interactions among these factors impact consumers' behaviour and increase the accuracy and validity of the research conclusions.

Considering that college students are the most active online buyers and have relatively superior learning ability and actual online purchase experience, the researchers recruited 110 college students with online shopping experience as participants and assigned them in an average and random manner to each platform. Each participant was compensated with 10 Chinese RMB (about US \$1.50) to engender participants' enthusiasm.

To facilitate the experimental needs, the researchers invited two programmers to develop the platforms. The 
format and outlet of the two platforms were designed to be similar to the layout of the Taobao app and website, and their commodity data were taken from real Taobao data to increase the authenticity of the experiment. Finally, to objectively track the online shopping behaviour, each participant's expense records and browsing paths (page navigation) were recorded automatically by the platforms during the experiment

To attain these objectives, the researchers ran the same experimental condition on different platforms and compared the results. Subjects were randomly allocated to 1 of 2 platforms and then were required to use the appropriate equipment (such as mobile phone, iPad, desktop computer and laptop) to access the corresponding platform to complete the experiment. The entire experimental process was divided into two stages. First, participants completed the questionnaire on the screen to enable the researchers to separate them into two groups in the data analysis phase: the "low" impulse group and the "high" impulse group. Second, participants imagined themselves as a shopper purchasing software. All steps were displayed on the Web pages.

\subsection{Experimental Process}

Consistent with the primitive commodity classification proposed by Nelson ([4], P.325), the researchers observed popular products' category words on Taobao (developed by Tencent Corp., China) and ruled out commodities that were particularly affected by age, climate, region, or gender. Finally, the researchers chose software as a technical product because of its low-cost advantage and high purchase frequency [24].

The product details page of the experiment includes product description, price, the retailer's credit level and an express delivery fee, among others. The researchers selected 100 software packages (price low than US \$15) from Taobaobased on sales volume and assigned them randomly to 10 experimental stores, with each store having 10 products. The programmers developed the two platforms by PHP and JAVA Script and plugged Baidu statistics code (developed by Baidu Corp., China) into them to record behaviour data. The platforms use the MYSQL database to store commodity information, questionnaire and consumption data.

The researchers used Rook and Fisher's measurement scale to measure consumers' impulse buying tendency [25]. To increase the rigor of the topic design of the scale, the researchers invited six e-commerce consumers who had rich online purchase experiences to fill out a prequestionnaire. According to their feedback and recommendations, a small proportion of dictions and pertinent structures were identified. Finally, the questionnaire was developed with nine items to answer using a five-point Likert scale ( $1=$ completely compatible, $5=$ completely incompatible).

Before the experiment was conducted, the researchers conducted a pre-test to exclude participants who had previously bought software. Subsequently, each standardcompliant subject was offered a unique individual account, and he (she) must use his (her) own equipment to access the corresponding platform. Operational information was on the first screen of the platform. At the beginning of the experiment, participants were told to read and follow the directions on the screen and buy software. The experiment had no time constraints, but participants had to complete the online shopping trip by themselves. Meanwhile, the participants did not know that their browsing history was being recorded until the completion of the experiment. However, to comply with the moral and ethical regulations of the university, the researchers informed the participants about the purpose of this study when the experiment ended. The guide map of Web pages consists of seven steps, as shown in Fig. 1.

1. Login page
This interface presented experimental instructions and required participants to
enter account numbers and passwords.

Figure 1 Guide map of web pages

\subsection{Experimental Details and Dependent Variables}

The two platforms did not have product review data because the third-party reviews of online stores could directly affect the impulse buying intention via consumers' pleasure and arousal. During the experiment, each participant was assigned 500 Chinese RMB (approximately US \$80) in virtual currency. The total budget control was reflected as each participant's assigned currency minus the total consumption expenditure; that is, a higher remaining balance indicated stricter budget control. The difficulty of the purchasing decision was measured by the number of shopping cart Web pages that a participant accesses; that is, the higher the number of times that the shopping cart page was visited, the more difficult the purchasing decision. Finally, the formulas for the time browsing the Web page and the time browsing the commodity details Web page are shown as follows.

Time spent browsing a Web page $=\frac{\text { Visit duration }}{\text { Pages views }}$

Time spent browsing a commodity details Web page =

$=\frac{\text { Visit duration of commodity details page }}{\text { Pages views of commodity details page }}$ 


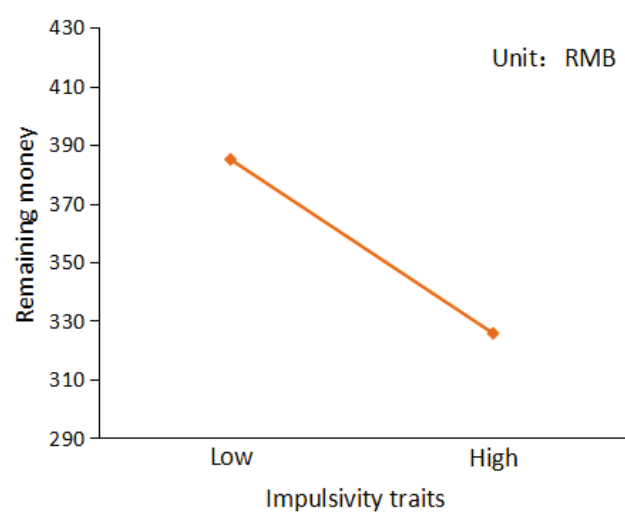

(a). Impulsivity traits for budget control

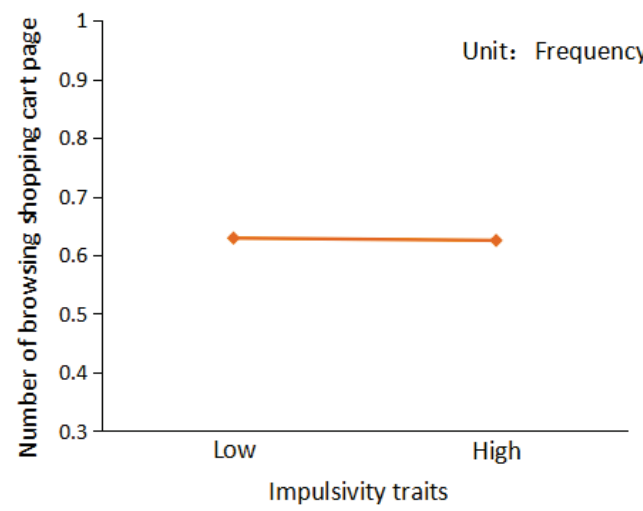

(c). Impulsivity traits for purchasing decision

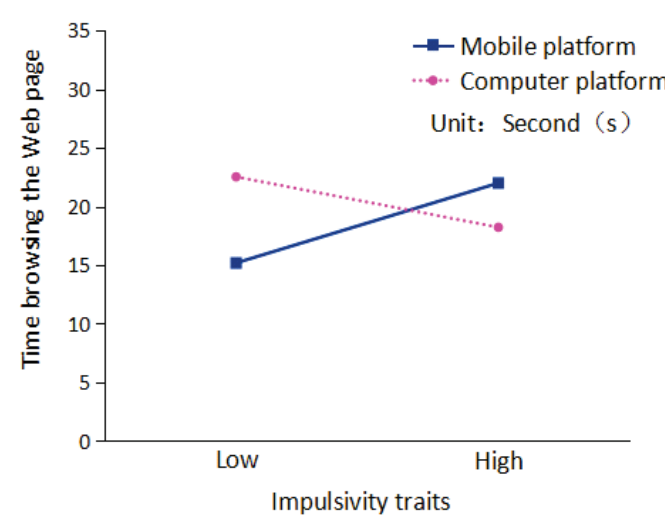

(e). Impulsivity traits $\times$ network platforms for the time browsing the Web page

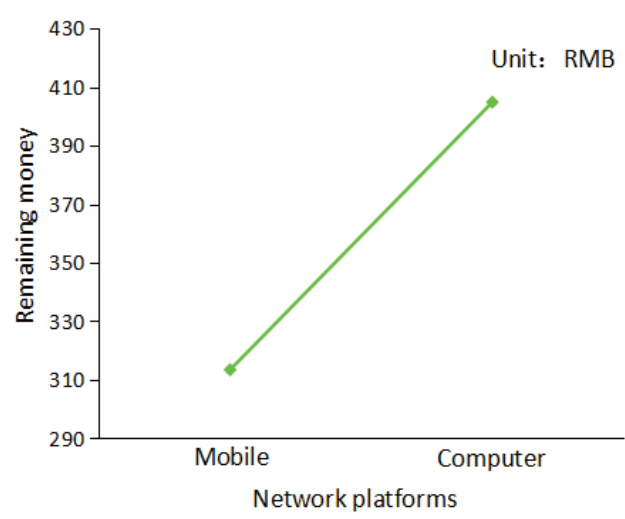

(b). Network platforms for budget control

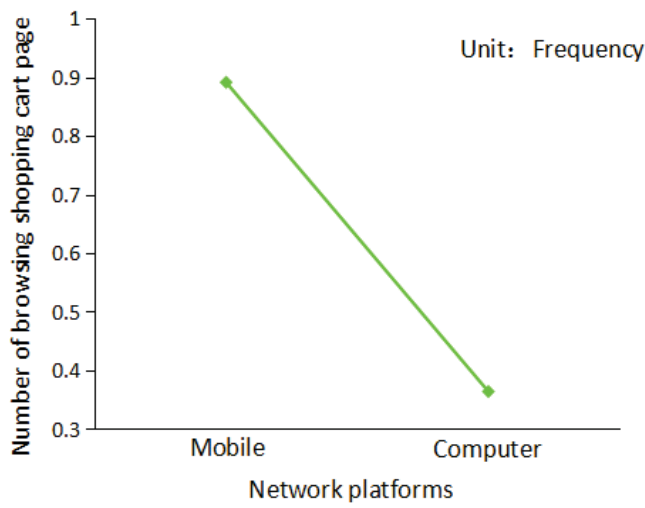

(d). Network platforms for purchasing decision

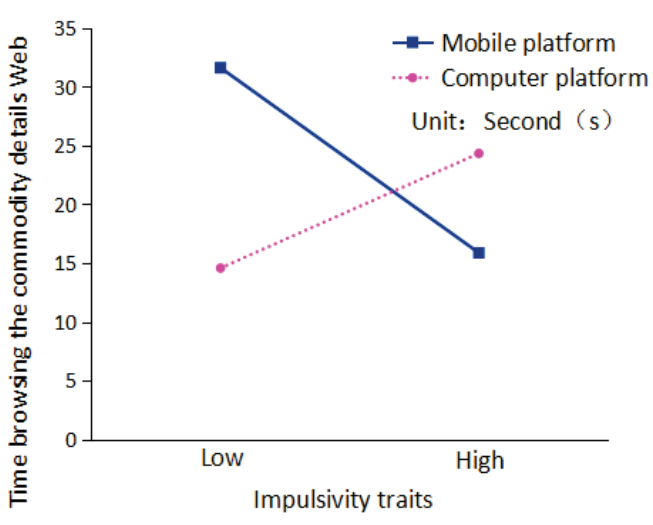

(f). Impulsivity traits $\times$ network platforms for the time browsing the commodity details Web page

Figure 2 Impulse buying by network platforms: Time spent browsing a Web page and time browsing a commodity details Web page

\section{RESULTS}

After collecting the behavioural data, prophase processing was carried out. The researchers used paired sample t-test and multiple regression analysis methods with impulse buying $\times$ network platforms to compare the differences between mobile and computer platform questionnaires and analysed the main factors affecting consumers' purchasing behaviour.

\subsection{Consumer Classification}

First, the researchers classified participants with having either "high" or "low" impulse buying tendencies according to the Consumer Impulse Buying Measurement
Scale. The result of the paired samples t-test showed that no significant difference existed between the mobile and the computer platforms' questionnaires $(p>0.05)$. Therefore, the researchers combined these two questionnaires to conduct a follow-up analysis. The new questionnaire had good reliability and construct validity, and its Cronbach's alpha coefficient and KMO statistic content were 0.762 and 0.744 , respectively. The confirmatory factor showed a good fit between the data and the construct of the scale. This questionnaire classified the impulse buying tendency with two scales based on the average score $(M=26.23)$ : participants whose scores were higher than the average were classified as high impulse buying tendency, and the rest were classified as low 
impulse buying tendency [12]. Consumer classification is shown in Tab. 1.

\begin{tabular}{|c|c|c|}
\hline & \multicolumn{2}{|c|}{ Impulse buying } \\
\hline Network platforms & $\begin{array}{c}\text { Low impulse } \\
\text { buying tendency }\end{array}$ & $\begin{array}{l}\text { High impulse buying } \\
\text { tendency }\end{array}$ \\
\hline Mobile platform & 32 & 23 \\
\hline Computer platform & 30 & 25 \\
\hline
\end{tabular}

\subsection{Hypothesis Testing}

Budget control: The results showed that impulse buying and network platforms had significant impacts on budget control $(r=.198, t=5.762, p<.05 ; r=.308, t=$ $11.565, p<.01)$. During an online shopping trip to purchase a technical product, low impulse participants executed more stringent budget control than high impulse participants ( $M=385.001$ vs. 325.695 RMB) (Fig. 2(a)). In addition, shoppers performed looser budget control when shopping on the mobile platform versus the computer platform ( $M=313.443$ vs. 404.801 RMB) (Fig. 2(b)). Therefore, both $\mathrm{H} 1$ and $\mathrm{H} 3$ are supported by the research results.

Purchasing decision: The results showed that no significant difference existed in the number of shopping cart pages browsed by low and high impulse participants $(r$ $=.008, t=1.448, p>.05 ; M=0.629$ vs. 0.625 pages) (Fig. 2 (c)). However, network platforms had a significant effect on the purchasing decision $(r=.194, t=-.325, p<.05)$. Participants made more difficult purchasing decisions on the mobile platform than on computers $(M=0.891$ vs. 0.364 pages) (Fig. 2(d)). Therefore, H4 is supported by the research results, but $\mathrm{H} 2$ is not.

Time spent browsing the Web page: The results showed that the interaction effects between impulse buying and network platforms had significant impacts on the time spent browsing a Web page $(r=.236, t=1.975, p<.05)$. When purchasing a technical product, low impulse participants spent less browsing time on the mobile platform $(M=15.179 \mathrm{~s})$ than on computers $(M=22.523 \mathrm{~s})$, whereas high impulse participants spent more time browsing a Web page on the mobile platform than on the computer platform $(M=21.990$ vs. $18.218 \mathrm{~s})$ (Fig. 2(e)). Therefore, H5 is supported by the research results.

Time spent browsing the commodity details Web page: The results demonstrated that the interaction effects between impulse buying and network platforms had significant impacts on the time spent browsing the commodity details Web page $(r=.332, t=1.019, p<.01)$. Participants with a low impulse buying tendency spent more time browsing each product on the mobile platform than on computers $(M=31.596$ vs. $14.569 \mathrm{~s})$. Furthermore, participants with a high impulse buying tendency spent less time browsing the commodity details Web page on the mobile platform than on the computer platform $(M=$ 15.865 vs. 24.315 s) (Fig. 2(f)). Therefore, H6 is supported by the research results.

\section{DISCUSSION}

This study employed two online platforms that simulated real shopping situations to investigate the effects of the interaction between impulse buying and network platforms on consumers' buying behaviour. The results of the experiments confirm some of the hypotheses. Hypothesis H1 suggests that stimulation and visceral pleasure constitute good justification for high impulsive online shoppers to purchase a technical product without guilt or regret, which confirms the findings in KukarKinney et al. [26] that the tendency to buy compulsively, Internet shopping and buying motivations exhibit positive linearity.

A large body of evidence indicates that different types of individual tendencies result in different manifestations of impulse buying. This conclusion can be summarized in three points: 1) product involvement has some influence on the impulse buying tendency; that is, the stronger the impulse buying tendency, the more time is spent on browsing products [27];2) during the same amount of time, high impulse buyers have a stronger impulse buying desire [3]; 3) consumers with a high impulse tendency are prone to generate positive emotions and make optimistic purchase evaluations [15]. However, hypothesis H2 - that consumers with a low impulse buying tendency make purchasing decisions with greater difficulty than those with high impulse buying tendency - is not supported, probably for the following two reasons. First, the assumption may be related to the technical product (software) selected by this experiment. Comparatively possible differences in perceived degrees of pleasure (such as flavour) exist for different people, perhaps because software is a type of information technology. Second, the assumption may be related to commodity type. Future studies might consider investigating the hypothesis based on other types of merchandise.

The results also suggest that consumers will spend more money and make more difficult purchasing decisions when buying a technical product on the mobile platform (H3, H4). H3 corresponds with the research that concluded that a combination of a smartphone and a tablet PC is the most profitable synchronization device [28]. H4 is similar to Drossos et al.[29] in that a highly effective and cognitive involvement product can cause lower purchase intentions when consumers respond to mobile text advertising. Meanwhile, Park and Salvendy [30] prove that advertising messages with large amounts of information may not suit mobile media on account of the restricted content capacity. Thus, a possible incident reason for the support of $\mathrm{H} 4$ is that, because of the limited size of the mobile device screen, consumers cannot obtain a thorough understanding of product information and spend more time comprehensively comparing and selecting their favourite commodities. Therefore, for an online store, paying more attention to the information arrangement and strengthening visual and sensory stimulation in mobile devices can constitute another important strategy for improving sales. Meanwhile, app designers should focus on recommending consumer context-awareness modules to help increase sales.

Previous studies on impulse buying have focused heavily on the cognitive and attitudinal aspects of consumers. The present study further combines these aspects with commodity type and network platforms to explore how consumers' internal interactions affect their shopping behaviour. The researchers found that when buying a technical product, consumers with low impulse 
buying tendency spend less time per page but more time per product on the mobile platform as opposed to consumers on the computer platform. Meanwhile, high impulse consumers present a contrary picture (H5, H6). This conclusion, on the one hand, demonstrates that low impulse buyers are inclined to linger on commodity pages and shop around. However, they do so likely because they prefer to use more online information when buying a technical product [31]. On the other hand, this conclusion shows that mobile online store designers should recognize that the commodity page layout occupies an important place in app design. In this case, the mobile platform's product information Web page must provide easy and intuitive cognition of all of the information, as well as a fast and convenient method for consumers to identify the commodity that they want to browse. If consumers do not feel that "screen shopping" is perceivable, desirable, comfortable and pleasant, they experience frustration and may even renounce or boycott the products and online stores that make them feel this way. Hence, shopping apps ought to take adequate measures, such as using the amusement characteristics of a technical product, to present an appropriately attractive view of commodity pages, provide adequate product/brand messages and make consumers perceive the store's implied sense of sincerity and intention when designing a product page.

\section{MARKETING IMPLICATIONS}

This study explores the effects of impulse buying and network platforms on the online buying behaviour of a technical product. The hypotheses tests support the validity of the majority of the suppositions. Based on this result, this study offers several implications for managers. First, from the managers' viewpoint, the research-supported hypothesis suggests that high impulse online shoppers purchase more products when buying technical products. Generally, good product managers need to grasp market trends, be familiar with customer groups for which their commodity is designed, set consumption trends and create consumption growth points [32]. In detail, the marketing procedure is about how to accurately grasp customer psychology related to precision marketing and impulse buying. For example, if a manager wants to hammer something into consumers' minds, modify attitudes, or prompt consumers to take some action, he or she must consider how to disseminate information to guide consumption. Likewise, for a technical product, asymmetric information quality exists between consumers and manufacturers. In accordance with customer demand and the experiential features of products, managers also need to develop marketing plans and arrange marketing channels.

Second, the investigation results demonstrate that managers need to note that mobile e-commerce is not the same as traditional e-commerce. How to maximize the utilization of the existing e-commerce platform and integrate $\mathrm{M}$-commerce with existing e-commerce platforms based on different application languages and platforms are important issues for current administrative staffs to resolve. From the point of view of participants' experimental results, in some respects, M-commerce cannot help consumers achieve the same objectives as easily as does e-commerce. A qualified manager should evaluate the following questions: How to effectively carry out the information layout on the mobile device screen? How to transplant the achievements of the traditional Web information platforms to mobile application platforms? How comfortable are consumers who obtain the same shopping experience on their personal computers and mobile phones?

Third, when the media content is not abundant, managers need to "manage" the product information made available to consumers. This study shows that consumers may undergo difficult decision-making processes in a comparably low media-rich environment. The layout of the commodity information and content should make it relatively simple to maintain a low cognitive load to prevent consumers from feeling "stressful" during the information search process. Therefore, distinguishing a good mobile application is particularly important for managers. To emphasize, managing the analytical process of adaptivity modelling the context of M-commerce applications contains four elements: who, what, when and where. The first three elements represent the application functionality (what) and the business rules for data access (who, when) and the fourth element indicates the user's location (where) [33]. Nevertheless, many applications often discard much valuable information that can provide users with better services and furnish customers with better overall use of feelings. For example, Yelp's application ignores the taste of a user's personal preferences and environmental factors. Amazon's PriceCheck application overlooks a user's historical purchase records. What type of mobile application will be appreciated by the consumer? Put simply, an application that meets the user's expectations should possess the following five features: practical function, easy operation, friendly interface, innovative technology and irreplaceable service. Therefore, managers need to better understand the degree of matching between application and product and guarantee that consumers do not experience negative emotions given low media richness levels.

\section{THEORETICAL CONTRIBUTION}

This research makes several theoretical and practical contributions. First, previous studies on impulse buying, network platforms and commodity types are fragmented. Although many empirical studies suggest that all of these attributes have a significant impact on customers' purchase behaviour, little effort has been made to combine and study them profoundly. The researchers have carried out a preliminary study on this aspect that can serve as an initial stepping stone to shed new light on future research. Meanwhile, the researchers consider this to be the most important theoretical contribution of this article.

Second, mobile platform data acquisition has always been a major problem in empirical research. In addition to mobile Internet enterprise and partial data analysis organizations, for ordinary researchers to obtain first-hand primitive monitor datum is very difficult. However, these data are precise and truly reflect the specific behaviour of consumers during the shopping process. Simultaneously, few comparative types of studies on consumer behaviour for the mobile and computer platforms exist. Therefore, the 
researchers adopted a flexible and effective measure - two platforms - to collect objective data to study the differences in consumers' online behaviour in the same shopping situation on the mobile and computer platforms. This approach may provide the basis and a useful reference for relevant future research and practice.

Third, this study contributes to promoting the development of the intersecting research field that covers subjects such as management, psychology, computer science and consumer behavioural science. At the same time, this study provides effective methods and thoughts for scientific research workers in fields such as information science, management science, cognitive science and prediction theory.

\section{LIMITATIONS AND FUTURE RESEARCH DIRECTIONS}

Given the depth of knowledge and research capacity constraints, this study faced certain limitations. First, to eliminate various factors, this research did not provide participants with subjective-based judgements, and categorized them within the same available budget. However, in an authentic purchasing situation, consumers have different consumption abilities and frequently require reference information on other buyers' shopping experiences. To address this limitation, the researchers could consider using real purchasing behaviour data to test these hypotheses in subsequent studies.

Second, experience and search goods represent the two extremes of product classifications, with most items falling somewhere in the middle [34]. Using clothes as an example, some consumers believe that they can obtain a general idea of the features after viewing size introductions and model diagrams, whereas others claim that they can determine whether or not a piece of clothing is a good match for them only after trying it on. Both sides clearly have their own merits. Future studies could explore how different consumer characteristics affect their perceptions of the dimensions of commodity classification.

Third, researchers have been trained to think that young participants are all proficient with the apps. However, there is a real possibility that different participants are accustomed to using different shopping apps and that even some have not used Taobao app very often. In view of the experimental results' symmetry, the researchers only consider the equal number of participants of the two platforms and choose to ignore the situation in which participants may not like to use the Taobao app. Taking the preciseness of the experiment into account, future research should pay more attention to this issue and conduct a more accurate preliminary screening for participants prior to the experiment.

Fourth, owing to the availability of experimental objects, this study only includes college students in the sample. Because all sorts of age groups due to their social background, income difference, and education level will have different online behaviour, the sample of this study presents limitations in that the findings may not be applicable to other populations. For future study, exploratory research on assumptions in broader consumer groups or comparative study among different participants categories is expected.
Finally, culture plays a significant role in consumer online purchasing behaviour [35]. It can assume that the argument and relative value of the method proposed in this study may differ by culture. Thus, the cultural variables could be included in future studies to further evaluate assumptions in the study.

\section{Acknowledgments}

This paper is supported by the National Natural Science Foundation of China (No: 71764006, No: $71363022)$

\section{REFERENCES}

[1] Pawan, K. (2015). Buying trend shifting of online shopping from e-com to m-com from "click" to "tap". Journal of Management Engineering and Information Technology, 2(3), 529-551.

[2] Lo, L. Y. S., Lin, S. W., \& Hsu, L. Y. (2016). Motivation for online impulse buying: A two-factor theory perspective. International Journal of Information Management, 36(5), 759-772. https://doi.org/10.1016/j.jijnfomgt.2016.04.012

[3] Beatty, S. E. \& Ferrell, M. E. (1998). Impulse buying: Modeling its precursors. Journal of Retailing, 74(2), 169191. https://doi.org/10.1016/S0022-4359(99)80092-X

[4] Finkelstein A., Harman M., Jia Y., MartinW., Sarro, F., \& Zhang Y. (2014). App store analysis: Mining app stores for relationships between customer, business and technical characteristics. Reseach Note RN/14/10 UCL Department of Computer Science, 14(10).

[5] Nelson, P. (1970). Information and consumer behavior. Journal of Political Economy, 78(2), 311-329. https://doi.org/10.1086/259630

[6] Klein, L. R. (1998). Evaluating the potential of interactive media through a new lens: Search versus experience goods. Journal of Business Research, 41(3), 195-203. https://doi.org/10.1016/S0148-2963(97)00062-3

[7] Neelamegham, R. \& Jain, D. (1999). Consumer choice process for experience goods: An econometric model and analysis. Journal of Marketing Research, 36(3), 373-386. https://doi.org/10.1177/002224379903600306

[8] Zhang, L., Zhu, J., \& Liu, Q. (2012). A meta-analysis of mobile commerce adoption and the moderating effect of culture. Computers in Human Behavior, 28(5), 1902-1911. https://doi.org/10.1016/j.chb.2012.05.008

[9] Zhao, Y., Ni, Q., \& Zhou, R. (2018). What factors influence the mobile health service adoption? A meta-analysis and the moderating role of age. International Journal of Information Management, 43, 342-350. https://doi.org/10.1016/j.jijinfomgt.2017.08.006

[10] Liu, Q. \& Zhang, L. (2014). Information cascades in online reading: an empirical investigation of panel data. Library $\mathrm{Hi}$ Tech, 32(4), 687-705. https://doi.org/10.1108/LHT-06-2014-0052

[11] Vohs, K. D. \& Faber, R. J. (2007). Spent resources: Selfregulatory resource availability affects impulse buying. Journal of Consumer Research, 33, 537-547. https://doi.org/10.1086/510228

[12] Verplanken, B. \& Herabadi, A. (2001). Individual differences in impulse buying tendency: Feeling and no thinking. European Journal of Personality, 15(1), 71-83. https://doi.org/10.1002/per.423

[13] Sharma, P., Sivakumaran, B., \& Marshall, R. (2010). Impulse buying and variety seeking: a trait-correlates perspective. Journal of Business Research, 63(3), 276-283. https://doi.org/10.1016/j.jbusres.2009.03.013 
[14] Mahdi, A. A. (1996). George Ritzer, Expressing America: A critique of the global gredit card society. Thousand Oaks, Ca: Pine Forge Press, Sociological Focus, 29(3), 281-283. https://doi.org/10.1080/00380237.1996.10570645

[15] Dawson, S. \& Kim, M. (2009). External and internal trigger cues of impulse buying online. Direct Marketing: An International Journal, 3(1), 20-34. https://doi.org/10.1108/17505930910945714

[16] Cheney, J. S. (2008). An examination of mobile banking and mobile payments: Building adoption as experience goods? Social Science Research Network, Rochester, NY.

[17] Ozer, L. \& Gultekin, B. (2015). Pre- and post-purchase stage in impulse buying: The role of mood and satisfaction. Journal of Retailing and Consumer Services, 22(C), 71-76. https://doi.org/10.1016/j.jretconser.2014.10.004

[18] Liu, Q., Huang, S., \& Zhang, L. (2016). The influence of information cascades on online purchase behaviors of search and experience products. Electronic Commerce Research, 16(4), 553-580. https://doi.org/10.1007/s10660-016-9220-0

[19] Liu, Q., Zhang, X., Zhang, L., \& Zhao, Y. (2018). The interaction effects of information cascades, word of mouth and recommendation systems on online reading behavior: an empirical investigation. Electronic Commerce Research, 127. https://doi.org/10.1007/s10660-018-9312-0

[20] Ye, Y., Zhao, Y., Shang, J., \& Zhang, L. (2019). A hybrid IT framework for identifying high-quality physicians using big data analytics. International Journal of Information Management, 47, 65-75. https://doi.org/10.1016/j.jijinfomgt.2019.01.005

[21] Bang, Y., Han, K., Animesh, A., \& Hwang, M. (2013). From online to mobile: Linking consumers' online purchase behaviors with mobile commerce adoption. Proceedings of 2013 Pacific Asia Conference on Information System, 128142.

[22] Wu, Y. \& Ye, Y.(2013). Understanding impulsive buying behavior in mobile commerce. Proceedings of 2013 Pacific Asia Conference on Information System, 142-159.

[23] Huang, P., Lurie, N.H., \& Mitra, S. (2009). Searching for experience on the web: An empirical examination of consumer behavior for search and experience goods. Journal of Marketing, 73(2), 55-69. https://doi.org/10.1509/jmkg.73.2.55

[24] Dijst, M., Farag, S., \& Schwanen, T. (2008). A comparative study of attitude theory and other theoretical models for understanding travel behaviour. Environment and Planning A: Economy and Space, 40(4), 831-847. https://doi.org/10.1068/a39151

[25] Rook, D. W. \& Fisher, R. J. (1995). Normative influences on impulsive buying behavior. Journal of Consumer Research, 22(3), 305-313. https://doi.org/10.1086/209452

[26]Kukar-Kinney, M., Ridgway, N. M., \& Monroe, K. B. (2009). The relationship between consumers' tendencies to buy compulsively and their motivations to shop and buy on the internet. Journal of Retailing, 85(3), 298-307. https://doi.org/10.1016/j.jretai.2009.05.002

[27] Liu, Q., Zhang, X., Huang, S., Zhang, L., \& Zhao, Y. (2020). Exploring consumers' buying behavior in a large online promotion activity: The role of psychological distance and involvement. Journal of Theoretical and Applied Electronic Commerce Research, 15(1), 66-80.

[28] Han, S., Ghose, A., \& Xu, K. (2013). Mobile commerce in the new tablet economy. Proceedings of the $34^{\text {th }}$ International Conference on Information Systems (ICIS), 118.

[29] Drossos, D. A., Kokkinaki, F., Giaglis, G. M., \& Fouskas, K. G. (2014). The effects of product involvement and impulse buying on purchase intentions in mobile text advertising. Electronic Commerce Research and Applications, 13(6), 423-430. https://doi.org/10.1016/j.elerap.2014.08.003
[30] Park, T. \& Salvendy, G. (2012). Emotional factors in advertising via mobile phones. International Journal of Human-Computer Interaction, 28(9), 597-612. https://doi.org/10.1080/10447318.2011.641899

[31] Bei, L. T., Chen, E. Y. I., \& Widdows, R. (2004) Consumers' online information search behavior and the phenomenon of search vs. experience products. Journal of Family and Economic Issues, 25(4), 449-467. https://doi.org/10.1007/s10834-004-5490-0

[32] Tang M., Qi Y., \& Zhang M. (2017). Impact of product modularityon mass customization capability:An exploratory study of contextual factors. International Journalof Information Technology \& Decision Making, 16(4), 939959. https://doi.org/10.1142/S0219622017410012

[33] Yinan Q., Tang M., \& Zhang M. (2014). Mass customization in flat organization: The mediating role of supply chain planning and corporation coordination. Journal of Applied Research and Technology, 12(2), 171-181. https://doi.org/10.1016/S1665-6423(14)72333-8

[34] Nelson, P. (1974). Advertising as information. Journal of Political Economy, 82(4), 729-754. https://doi.org/10.1086/260231

[35] Zhao, Y., Li, K., \& Zhang, L. (2019). A meta-analysis of online health adoption and the moderating effect of economic development level. International Journal of Medical Informatics, 127, 68-79. https://doi.org/10.1016/j.jimedinf.2019.04.015

\section{Contact information:}

\section{Xuan WEN, PhD}

(Corresponding author)

School of Information Management, Wuhan University,

No. 299 Bayi Road, Wuchang District, Wuhan City, Hubei Province, China

E-mail: Xuan_W113@163.com

\section{Yiran LI PhD}

School of Information Management, Wuhan University, No. 299 Bayi Road, Wuchang District, Wuhan City, Hubei Province, China E-mail: yiran.li@whu.edu.cn

\section{Qihua LIU, PhD}

(Corresponding author)

School of Economics and Management, Hainan University, No. 58 RenminRoad, Haikou City, Hainan Province, China

School of Information Management, Jiangxi University of Finance and Economics, Yuping Avenue, Changbei Economic and Technological Development Zone, Nanchang City, Jiangxi Province, China E-mail: qh_liu@163.com 